\title{
Anemia in the Elderly: Neuropsychiatric Repercussions
}

\author{
Barbara Gazolla Macedo', Poliana P. R. Dias², Hanna S. Camara², Carlos Maurício F. Antunes² \\ ${ }^{1}$ Instituto da Previdência dos Sevidores do Estado de Minas Gerais/IPSEMG, Belo Horizonte, Brasil \\ ${ }^{2}$ Instituto de Ensino e Pesquisa da Santa Casa de Belo Horizonte/IEP, Belo Horizonte, Brasil \\ Email: barbaragazolla@terra.com.br
}

How to cite this paper: Macedo, B.G., Dias, P.P.R., Camara, H.S. and Antunes, C.M.F. (2017) Anemia in the Elderly: Neuropsychiatric Repercussions. Advances in Aging Research, 6, 11-16.

http://dx.doi.org/10.4236/aar.2017.61002

Received: October 25, 2016

Accepted: December 27, 2016

Published: December 30, 2016

Copyright (c) 2017 by authors and Scientific Research Publishing Inc. This work is licensed under the Creative Commons Attribution International License (CC BY 4.0).

http://creativecommons.org/licenses/by/4.0/

Open Access

\begin{abstract}
The purpose of this review is to evaluate the role of chronic anemia on neuropsychiatric symptoms and conditions among the elderly. Anemia is defined as hemoglobin levels below 120 and $130 \mathrm{~g} / \mathrm{L}$ for women and men, respectively. Anemia is not a consequence of the aging process. It is common in the elderly and easily overlooked. Nevertheless, chronic anemia is a risk factor associated with increased mortality, several geriatric syndromes including functional and cognitive impairments. Investigations have shown that anemic elderly and those with hemoglobin borderline levels may present higher proportion of neuropsychiatric impairment, such as Executive Function Disorder and Alzheimer disease. The association between anemia and depression is well established, but its causal pathway is not known: anemia can be regarded as cause or consequence of depression. There is evidence that dementia due to anemia can be prevented; renal chronic anemic patients who received erythropoietin (EPO) replacement therapy showed a lower risk for dementia, compared to those who did not receive it. Anemia may be associated with chronic psychiatric diseases such as bipolar disorders and cause their symptoms to become more severe.
\end{abstract}

\section{Keywords}

Anemia, Elderly, Cognitive Impairment, Neuropsychiatric Disorders

\section{Introduction}

The World Health Organization criteria define anemia as hemoglobin levels below 120 and $130 \mathrm{~g} / \mathrm{L}$ for women and men respectively. It is the most frequently used in scientific articles, although not universally accepted [1]. Several investigations have shown that elderly patients with anemia, including those with borderline hemoglobin levels, have higher rates of neuropsychiatric symptoms [2]- 
[7].

Approximately one third of anemia cases can be associated with nutritional deficiencies; another third with chronic inflammation and kidney diseases and the last third do not show association to specific etiologies [3] [4] [5].

Anemia prevalence increases with age, particularly in those aged 85 and over. Recent investigations report higher prevalence of anemia in this age group, 2 to 3 times higher when compared to people into 64 to 69 year age group. However, anemia prevalence may vary among population groups, e.g., elderly living in the community, or in nursing homes, or seen at outpatient clinics or hospitalized. The healthy status may be a plausible explanation for the observed difference. Among those living in the community, it is estimated that 1 out of $7-8$ elderly have anemia; in nursing homes and hospitals, the ratio increases to 1 out of 2 old persons [3] [4] [5] [6] [7].

Even though anemia is not considered a consequence of the aging process, it is commonly reported in the elderly and frequently not treated. However, chronic anemia is a risk factor associated to increased mortality, functional and cognitive impairment, several geriatric syndromes as dementia, delirium, depression and falls [7] [8] [9] [10].

The purpose of this review is to evaluate the implication of chronic anemia in the elderly on neuropsychiatric symptoms and conditions.

\section{Methodology}

The research on biomedical literature over the last 15 years, from PubMed and Lilacs databases showed articles associating chronic anemia and neuropsychiatric symptoms. Inclusion criteria were articles published in English, Spanish or Portuguese on people aged 65 and over, animal studies were not included. Nine articles meeting inclusion criteria were identified.

\section{Acute and Chronic Anemia}

Anemia may be classified as acute or chronic according to its signs and symptoms, which varies with the disease course [2] [3].

In acute conditions, blood volume is more important than hemoglobin level; a $10 \%$ decrease in total volume is well tolerated. Decreases between $10 \%$ and $20 \%$ are frequently associated to postural hypotension, dizziness and fainting. Tachycardia, cold extremities, paleness of the skin and hypotension are commonly reported in blood losses higher than $20 \%$. A decrease higher than $30 \%$, if not immediately replaced, can lead to fatal shock.

In chronic anemia, a decrease in blood volume is not observed, once there is an increase in plasma levels. Low hemoglobin count together with reduced red blood cell mass is responsible for the oxygen depletion in the organism. The main systems and organs affected are the Central Nervous System, heart, and muscles, due to their higher oxygen uptake. The perception of signs and symptoms by the elderly is not as intense as those reported by younger patients. This 
fact may be the key element in anemia persistence among this population. Chronic non-treated anemia may lead to depression, cognitive impairment and an exacerbation of pre-existing psychiatric conditions.

\section{Anemia, Cognition and Dementia}

In a cohort study including 1435 community elderly (Women Health and Aging Study-WHAS II), age 75 - 95 years, revealed an independent association between anemia and an increase in risk of dementia diagnosis. Mild anemia was also associated with cognitive impairment, especially those linked to executive functions. Executive functions include task planning and problem solving. It should be pointed out that it may occur in elderly without dementia; they can precede deficits in other cognitive function domains, acting as a risk factor for the decline or inability to perform the activities of daily living [11] [12].

The dementia risk is greater in the presence of anemia, as evidenced in another cohort investigation. Anemic elderly without cognitive impairment were found to have a higher probability to develop dementia in the next five years, compared to non-anemic same age participants. The same association was observed in the Established Population for Epidemiological Studies of the Elderly-EPESE [13] [14].

Mild anemia (10 - $12 \mathrm{~g} / \mathrm{dl})$ was associated with a decline in executive function. Elderly women (364) aged $70-80$ years, active and living in the community, with mild anemia, had a four-time worse performance in executive functions than non-anemic control group. It was also observed, that non-anemic with hemoglobin levels close to the lower normal limit may present cognitive impairment and Alzheimer disease [12] [13] [15].

In order to investigate the role of lower hemoglobin levels in the development of common neurologic diseases associated with aging and cognitive decline, 113 elderly people living in the community had their lives examined until they passed away. The results, categorized according to the criteria age at death, gender and education level, showed that lower hemoglobin levels were associated with chronic macroscopic infarction but not to other neurologic diseases [16].

There is evidence that dementia due to anemia can be prevented; renal chronic anemic patients who received erythropoietin (EPO) replacement as therapy, showed a lower risk for dementia, compared to those who did not received it [17].

Presently, there are few pathways to explain the correlation between the increase of anemia prevalence and aging. In the aging process, there is an augment in EPO demand. Healthy elderly, who have higher EPO levels, are more apt to challenge the aging process; those who have EPO production diminished may develop anemia. Aging is also linked to an increase in the expression of inflammatory cytokines, which can inhibit EPO activity or production. Elderly presenting genetic cytokine polymorphisms can develop anemia due to an increased hepcidin expression or red blood cell colonies suppression [17]. 


\section{Anemia, Depression and Other Psychiatric Disorders}

The association between anemia and depression is well established, but causal pathway is not known: it can be regarded as cause or consequence of depression. Anemia can be the cause of depression as a result of vitamin deficiency (folic acid and B12), leading to a decreased S-adenine-methionine or to an increase of homocysteine production. S-adenine-methionine participates in neurotransmitter synthesis, including especially serotonin (5HT), dopamine (DA), and noradrenaline (NA). The synthesis of methionine from homocysteine requires a supply of methyl groups from methyl folate, and vitamin B12 as a cofactor. Thus functional deficiency of either vitamin can lead in raised concentrations of homocysteine. Methionine is the immediate precursor of S-adenosylmethionine, the methyl donor in numerous methylation reactions in the brain. Homocysteine accumulation can affect central nervous system receptors. It is toxic to neurons and blood vessels and can induce DNA strand breakage, oxidative stress, and apoptosis [18]. Notwithstanding, depression may have an important role in anemia development. Depression symptoms as fatigue and lack of interest in daily activities can affect the elderly food intake quality, leading to the development of anemia. A recent investigation reported this association after controlling for vitamin B12 deficiency and presence of co-morbidities. In another investigation, anemic patients with deficiency in vitamin B6 and folic acid showed depression symptoms [19] [20].

Anemia may be associated with several chronic psychiatric disorders; it has been diagnosed in $22 \%, 25 \%$ and $24 \%$ of patients with depression, bipolar and conversion disorders, respectively. The severity of these conditions is exacerbated by anemia. If not treated, it can lead to exacerbated exhaustion, fatigue and cognitive impairment [19] [20].

\section{Final Considerations}

Elderly population is currently increasing, especially those 80 and over, with a concomitant increase in depression, dementia and cognitive impairment risk. If anemia is truly associated with those conditions, treatment should be given, either to anemic patients or to those with borderline hemoglobin level. As hemoglobin level measure is routinely carried out for a vast majority of those seeking medical care, then anemia can be used as a flag to identify elderly at high risk to present neuropsychiatric disorders.

More investigations are needed to evaluate the impact of anemia and its treatment in dementia and cognitive impairment. Large cohort studies and trials using more specific hemoglobin level definition and cognitive function evaluation should be conducted. Benefits and risks of anemia treatment and its impact on elderly neuropsychiatric disorders should be better established.

\section{Acknowledgements}

The authors acknowledge the support of Fundação de Amparo à Pesquisa do Estado de Minas Gerais (FAPEMIG) and Conselho Nacional de Desenvolvi- 
mento Científico e Tecnológico (CNPq).

\section{References}

[1] World Health Organization (1968) Nutritional Anaemias. Report of a WHO Scientific Group. Technical Report Series No. 405, Geneva.

[2] Bianchi, E. (2014) Anemia in the Elderly Population. Journal of Hematology, 3, 95-106. https://doi.org/10.14740/jh182w

[3] Gaskell, H., Derry, S., Moore, R.A. and McQuay, H.J. (2008) Prevalence of Anaemia in Older Persons: Systematic Review. BMC Geriatrics, 8, 1.

http://www.biomedcentral.com/1471-2318/8/1

https://doi.org/10.1186/1471-2318-8-1

[4] Begh, C., Wilson, A. and Ershler, W.B. (2004) Prevalence and Outcomes of Anemia in Geriatrics: A Systematic Review of the Literature. American Journal of Medicine, 116, 3S-10S. https://doi.org/10.1016/j.amjmed.2003.12.009

[5] Merchant, A.A. and Roy, C.N. (2012) Not So Benign Haematology: Anaemia of the Elderly. British Journal of Haematology, 156, 173-185.

https://doi.org/10.1111/j.1365-2141.2011.08920.x

[6] Atti, A.R., Palmer, K., Volpato, S., Zuliani, G., Winblad, D. and Fratiglioni, L. (2006) Anemia Increases the Risk of Dementia in Cognitively Intact Elderly. Neurobiology of Aging, 27, 278-284.

https://doi.org/10.1016/j.neurobiolaging.2005.02.007

[7] Bosco, R.M., Assis, E. and Antunes, C.M.F. (2013) Anemia e capacidade funcional em idosos brasileiros hospitalizados. Cadernos de Saúde Pública, 29, 1322-1332. https://doi.org/10.1590/S0102-311X2013001100007

[8] Goodnough, L.T. and Schrier, S.L. (2014) Evaluation and Management of Anemia in the Elderly. American Journal of Hematology, 89, 88-96.

https://doi.org/10.1002/ajh.23598

[9] Denny, S.D., Kuchibhatla, M.N. and Cohen, H.J. (2006) Impact of Anemia on Mortality, Cognition, and Function in Community-Dwelling Elderly. American Journal of Medicine, 119, 327-334. https://doi.org/10.1016/j.amjmed.2005.08.027

[10] Chaves, P.H., Ashar, B., Guralnik, J.M. and Friedl, L.P. (2002) Looking at the Relationship between Hemoglobin Concentration and Prevalent Mobility Difficulty in Older Women. Should the Criteria Currently Used to Define Anemia in Older People Be Reevaluated? Journal of the American Geriatrics Society, 50, 1257-1264. https://doi.org/10.1046/j.1532-5415.2002.50313.x

[11] Chaves, P.H.M., Carlson, M.C., Ferrucci, L., Guralnik, J.M., Semba, R. and Fried, L.P. (2006) Association between Mild Anemia and Executive Function Impairment in Community Dwelling Older Women: The Women's Health and Aging Study II. Journal of the American Geriatrics Society, 54, 1429-1435. https://doi.org/10.1111/j.1532-5415.2006.00863.x

[12] Lucca, U., Tettamanti, M., Mosconi, P., Apolone, G., Gandini, F., Nobili, A., Tallone, M.V., Detoma, P., et al. (2008) Association of Mild Anemia with Cognitive, Functional, Mood and Quality of Life Outcomes in the Elderly: The "Health and Anemia" Study. PLos ONE, 3, e1920. https://doi.org/10.1371/journal.pone.0001920

[13] Peters, R., Burch, L., Warner, J., Beckett, N., Poulter, R. and Bulpitt, C. (2008) Haemoglobin, Anaemia, Dementia and Cognitive Decline in the Elderly: A Systematic Review. BMC Geriatrics, 8, 18. https://doi.org/10.1186/1471-2318-8-18

[14] Shah, R.C., Buchman, A.S., Wilson, R.S., Leurgans, S.E. and Bennett, D.A. (2011) Hemoglobin Level in Older Persons and Incident Alzheimer Disease Prospective 
Cohort Analysis. Neurology, 77, 219-226.

https://doi.org/10.1212/WNL.0b013e318225aaa9

[15] Shah, R.C., Wilson, R.S., Tang, Y., Dong, X., Murray, A. and Bennett, D.A. (2009) Relation of Hemoglobin to Level of Cognitive Function in Older Persons. Neuroepidemiology, 32, 40-46. https://doi.org/10.1159/000170905

[16] Jonassaint, C.R., et al. (2014) Lower Hemoglobin Is Associated with pooRer Cognitive Performance and Smaller Brain Volume in Older Adults. Journal of the American Geriatrics Society, 62, 972-973. https://doi.org/10.1111/jgs.12810

[17] Ershler, W.B., Artz, A.S. and Kandahari, M.M. (2001) Recombinant Erythropoietin Treatment of Anemia in Older Adults. Journal of the American Geriatrics Society, 49, 1396-1397. https://doi.org/10.1046/j.1532-5415.2001.49275.x

[18] Bottiglieri, T., Laundy, M., Crellin, R., Toone, B.K., Carney, M.W.P. and Reynolds, E.H. (2000) Homocysteine, Folate, Methylation, and Monoamine Metabolism in Depression. Journal of Neurology Neurosurgery and Psychiatry, 69, 228-232. https://doi.org/10.1136/jnnp.69.2.228

[19] Korkmaz, S., et al. (2015) Frequency of Anemia in Chronic Psychiatry Patients. Neuropsychiatric Disease and Treatment, 11, 2737-2741. https://doi.org/10.2147/NDT.S91581

[20] Shah, R.C., Sheneider, J.A., Wilson, R.S., Leurgans, S.E. and Bennett, D.A. (2012) Association of Lower Hemoglobin Level and Neuropathology in CommunityDwelling Older Persons. Journal of Alzheimer's Disease, 32, 579-586.

Submit or recommend next manuscript to SCIRP and we will provide best service for you:

Accepting pre-submission inquiries through Email, Facebook, LinkedIn, Twitter, etc. A wide selection of journals (inclusive of 9 subjects, more than 200 journals)

Providing 24-hour high-quality service

User-friendly online submission system

Fair and swift peer-review system

Efficient typesetting and proofreading procedure

Display of the result of downloads and visits, as well as the number of cited articles

Maximum dissemination of your research work

Submit your manuscript at: http://papersubmission.scirp.org/

Or contact aar@scirp.org 